\title{
TINGKAT PEMAHAMAN DAN SIKAP REMAJA TERHADAP PROGRAM PENDEWASAAN USIA PERKAWINAN MELALUI FILM 'KEMBANG DESO' DI SMA NEGERI 5 MAKASSAR DAN MAN 2 MODEL MAKASSAR
}

\section{The Understanding and Attitude Levels of Adolescents Towards the Marriage Age Maturation Progam Through the Film "Kembang Deso" in SMA Negeri 5 and MAN 2 Model Makassasr}

\author{
Nathalia Debora Sidabutar, ${ }^{1}$ Hafied Cangara, ${ }^{2}$ Muhammad Farid ${ }^{3}$ \\ ${ }^{1}$ Mahasiswa Pascasarjana Ilmu Komunikasi, Fakultas Ilmu Sosial dan Politik, Universitas Hasanuddin \\ (Email: lhya_aza@yahoo.co.id) \\ ${ }^{2}$ Dosen Ilmu Komunikasi, Fakultas Ilmu Sosial dan Politik, Universitas Hasanuddin \\ (Email: cangara_hafied@yahoo.com) \\ ${ }^{3}$ Dosen Ilmu Komunikasi, Fakultas Ilmu Sosial dan Politik, Universitas Hasanuddin \\ (Email: faridemsil@yahoo.com)
}

\begin{abstract}
ABSTRAK
Program Pembangunan selalu membutuhkan peran komunikasi sebagai proses penyampaian dan penerimaan pesan dalam rangka meningkatkan dan memanfaatkan pengetahuan, sikap dan perilaku masyarakat dalam mendorong agar secara sadar menerima program pengendalian kependudukan dan keluarga berencana. Penelitian ini bertujuan untuk mengetahui tingkat pemahaman dan sikap remaja terhadap program Pendewasaan Usia Perkawinan melalui film 'Kembang Deso' dan melihat perbedaan pemahaman dan sikap remaja terhadap program Pendewasaan Usia Perkawinan. Penelitian ini merupakan penelitian kuantitatif yang berupa membandingkan dua objek penelitian yaitu siswa-siswi SMA Negeri 5 Makassar dengan siswa- siswi MAN 2 Model Makassar. Responden sebanyak 89 orang. Data dianalisis menggunakan model bivariat dengan uji T sampel independen. Hasil penelitian menunjukkan bahwa tidak ada perbedaan pemahaman terhadap program Pendewasaan Usia Perkawinan antara siswa-siswa SMA Negeri

5 Makassar dan siswa-siswa MAN 2 Model Makassar. Akan tetapi, dari sikap mereka terhadap program Pendewasaan Usia Perkawinan menunjukkan ada perbedaan yakni siswa-siswi SMA Negeri 5 Makassar berada pada kriteria setuju sedangkan siswa-siswi MAN 2 Model Makassar berada pada posisi netral. Perbedaan ini dilatarbelakangi perbedaan karakteristik sekolah yakni SMA Negeri 5 Makassar mewakili sekolah umum yang memiliki siswa yang lebih variatif dari segi etnis dan agama, sedangkan siswa MAN 2 Model Makassar adalah lembaga pendidikan yang mewakili sekolah berbasis agama (pesantren).
\end{abstract}

Kata Kunci: Film, Remaja, Pemahaman, Sikap, program Pendewasaan Usia Perkawinan

\section{ABSTRACT}

Program development needs the role of communication as in the process of delivering and receiving messages in order to enhance and leverage the knowledge, attitudes and behavior in order to quickly push consciously accept the program of population control and family planning. This study aimed to analyze the understanding and attitude levels of adolescents toward the Maturation Age Marriage Program through 'Kembang Deso' film and to look at the differences in the understanding and attitudes of teenagers towards the Maturation Age Marriage Program. This research was a quantitative study which compared two objects of study, namely between the students of SMA Negeri 5 and the students of MAN 2 Model, Makassar, comprising 89 respondents.The data were analyzed using bivariate models with the independent sample t test. The research results indicated that the two schools,- SMA Negeri 5 and

MAN 2 Model, Makassar - showed no difference in their understanding about the Maturation Age Marriage program. However, the students of SMA Negeri 5 had the attitudes to agree with the Maturation Age Marriage 
program, while the students MAN 2 Model, Makassar choose to take the neutral position towards the program. This difference was motivated by the different characteristics of the two schools: SMA Negeri 5, Makassar, is representing the public schools which had more varie students in terms of ethnicity and religions, while MAN 2 Model, Makassar, is an institution which representing Islamic religious schools (pesantrin).

Keywords: Film, teenegers, understanding, attitudes, Maturation Age Marriage Program

\section{PENDAHULUAN}

Pertumbuhan populasi dunia terjadi begitu cepat dari masa ke masa. Pertumbuhan yang tidak terkendali akan menyebabkan kepadatan penduduk (Muchtar, 2014). Pertambahan penduduk yang tidak diimbangi dengan penduduk yang berkualitas, maka akan menjadi beban negara dalam memenuhi kebutuhan dasar penduduk serta kehidupan sosial kemasyarakatan, sebaliknya akan menjadi investasi negara bila pertambahan penduduk diimbangi dengan penduduk yang berkualitas. Salah satu ciri negara berkembang adalah negara itu akan memperlihatkan fertilitas jauh lebih tinggi dibandingkan negara maju. Hal ini terkait dengan usia kawin pertama wanita dimana semakin muda usia wanita pada perkawinan pertama maka kecenderungan untuk memiliki anak lebih banyak akan semakin tinggi dan semakin besar resiko yang dihadapi selama kehamilan atau melahirkan, bagi keselamatan ibu maupun anaknya dikarenakan belum matangnya rahim wanita dalam perkembangan janinnya serta belum siap mental menghadapi masa kehamilan. Di Indonesia, angka statistika pernikahan usia dini dengan pengantin berumur dibawah usia 16 tahun secara nasional mencapai lebih seperempat, bahkan dibeberapa daerah, sepertiga pernikahan yang terjadi tepatnya di Jawa Timur (39.43\%), Kalimantan Selatan $(35,48 \%)$, Jambi $(30.63 \%)$, dan Jawa Barat (36\%) (Landung dkk., 2009).

Undang-undang nomor 1 tahun 1974 merupakan hukum positif yang dipakai sebagai acuan bagi seseorang untuk melaksanakan proses perkawinan. Pasal 7 ayat 1 menjelaskan bahwa perkawinan yang diizinkan jika laki-laki mencapai usia 19 tahun dan pihak perempuan mencapai usia 16 tahun. Sedangkan usia ideal dalam melaksanakan pernikahan menurut kesehatan dan program KB adalah pada usia 21 tahun untuk perempuan dan usia 25 tahun untuk laki-laki dengan pertimbangan pada usia tersebut organ reproduksi dan psikologis perempuan sudah berkembang, kuat serta siap melahirkan dan secara fisik juga mulai matang. Sementara laki-laki pada usia tersebut, kondisi psikis atau fisik sudah kuat sehingga mampu menopang dan melindungi kehidupan keluarga, baik psikis-emosional, ekonomi dan sosial (Arif, 2010).

Program pembangunan selalu membutuhkan peran komunikasi salah satunya adalah melakukan komunikasi, Informasi dan Edukasi (KIE) yang merupakan proses penyampaian dan penerimaan pesan dalam rangka meningkatkan dan memanfaatkan pengetahuan, sikap dan perilaku masyarakat dan mendorongnya agar secara sadar menerima program pengendalian kependudukan dan keluarga berencana. Komunikasi bermedia massa seperti koran, televisi dan film telah lama memerankan peran penting dalam mengemas dan mentransimisikan informasi budaya. Salurannya mempunyai daya jangkauan khalayak yang luas bahkan tidak terbatas serta kemampuannya cepat. (Riswandi, 2009). Film menjadi tempat yang sangat istimewa dalam budaya kita. Kekuasaan isi film lebih baik dari pada isi cerita di televisi. Penontonnya adalah berusia muda dimana remaja dan orang dewasa bisa menghabiskan 8 jam sehari menonton televisi, pergi di bioskop, dll (Baran, 2011).

Berdasarkan latar belakang diatas maka penulis tertarik meneliti dengan judul tingkat pemahaman dan sikap remaja terhadap program Pendewasaan Usia Perkawinan Melalui Film 'Kembang Deso'. Adapun tujuan penelitian ini untuk mengetahui tingkat pemahaman dan sikap remaja terhadap program Pendewasaan Usia Perkawinan, menganalisis perbedaan pemahaman dan sikap di SMA Negeri 5 Makasar dan MAN 2 Model Makassar, serta mengetahui hubungan pemahaman dengan sikap remaja terhadap program Pendewasaan Usia Perkawinan.

\section{METODE PENELITIAN}

\section{LOKASI DAN RANCANGAN PENELITIAN}

Metode yang digunakan pada penelitian ini adalah komperatif deskriptif dimana menyajikan suatu gambaran fenomena yang ada dengan membandingkan variabel 
yang sama untuk sampel yang berbeda (Riduwan, 2008). Penelitian dilakukan dari bulan April sampai dengan Mei 2016 di SMA Negeri 5 Makassar dan MAN 2 Model Makassar.

\section{POPULASI DAN SAMPEL}

Populasi penelitian ini adalah seluruh siswa kelas XI di SMA Negeri 5 Makassar dengan jumlah 432 orang siswa dan MAN 2 Model Makassar dengan jumlah 376 orang siswa. Jadi, keseluruhan populasi penelitian ini adalah 808 orang siswa. Teknik pengambilan sampel menggunakan formula Slovin dengan tingkat kekeliruan $10 \%$ sehingga didapatkan besar sampel adalah 89 orang siswa dipilih menggunakan metode stratified random sampling dimana memilih sampel berdasarkan kelompok kecil atau cluster. Maka besaran sampel adalah 41 orang siswa MAN 2 Model Makassar dan 48 orang siswa SMA Negeri 5 Makassar.

\section{METODE PENGUMPULAN DATA}

Teknik pengumpulan data penelitian ini menggunakan instrumen koesioner dengan menggunakan skala likerts yang dikategorikan menjadi 4 kriteria dan skala ordinal untuk karakteristik responden. Data karakteristik responden berupa umur, jenis kelamin, suku, pendidikan orang tua, pekerjaan orang tua, transportasi, tinggal bersama. Data tingkat pemahaman

dan sikap memiliki indikator berupa pengertian program Pendewasaan Usia Perkawinan, tujuan Pernikahan, batas umur pernikahan, kehamilan di usia muda, peran dan tanggung jawab anggota keluarga dan dampak yang mungkin terjadi bila menikah muda,

\section{KRITERIA PENILAIAN DATA PENELITIAN}

Penelitian ini menggunakan 3 (tiga) kriteria data yaitu: tinggi-sedang-rendah untuk tingkat pemahaman dan setuju-netraltidak setuju untuk sikap, dengan menggunakan rumus:

$$
\begin{aligned}
& \text { - } \mathrm{X}>(\mathrm{M}+1 * \mathrm{SD}) \rightarrow \text { Tinggi/Setuju } \\
& \cdot \quad \begin{array}{l}
(\mathrm{M}-1 * \mathrm{SD}) \leq \mathrm{X} \leq(\mathrm{M}+1 * \mathrm{SD}) \\
\rightarrow \text { Sedang/netral }
\end{array}
\end{aligned}
$$$$
\text { - } \mathrm{X}<(\mathrm{M}-1 * \mathrm{SD}) \rightarrow \text { Rendah/Tidak Setuju }
$$

\section{ANALIS DATA}

Teknik analisis penelitian ini adalah analisis bivariat dengan menggunakan uji $T$ sample Indenpenden untuk membandingkan variabel tingkat pemahaman dan sikap remaja. Sedangkan untuk mengetahui hubungan tingkat pemahaman dan sikap menggunakan uji regresi linier. Karakteristik responden diolah menggunakan tabel frekuensi distribusi sederhana. Dalam menganalisis data penelitian ini, peneliti dibantu menggunakan aplikasi SPSS Versi 22.00.

\section{HASIL}

\section{KARAKTERISTIK RESPONDEN}

Masa remaja adalah masa peralihan atau masa transisi dari anak-anak menuju masa dewasa. Persiapan untuk memasuki masa dewasa meliputi perubahan fisik, perubahan sosial, bertambahnya kemampuan dan keterampilan. Akibat perubahan tersebut, remaja juga akan mengalami perubahan tingkah laku yang dapat menimbulkan konflik dengan orang sekitarnya.

Hasil penelitian secara deskriptif menunjukkan bahwa siswa-siswi tersebut berumur 16 tahun dimana sebanyak 20 orang (48.8\%) dari MAN 2 Model Makassar dan sebanyak 28 orang (58.3\%) dari SMA Negeri 5 Makassar. Ketidakseimbangan emosional dan ketidakstabilan dalam banyak hal terdapat masa ini. Remaja berupaya mencari identitas dirinya sehingga statusnya tidak jelas. Selain itu, pada masa ini terjadi perubahan pola-pola hubungan sosial. Sebagian besar responden berlatarbelakang suku Bugis dimana 28 orang (68.3\%) dari MAN 2 Model Makassar dan 28 Orang (58.3) dari SMA Negeri 5 Makassar. Kondisi diatas menunjukkan bahwa persebaran latar belakang suku responden telah beragam walaupun sebagian besar merupakan penduduk asli Sulawesi Selatan yaitu suku Bugis, Makassar, Toraja dan Mandar. Sebagian besar responden beragama Islam yaitu 41 orang (100\%) dari MAN 2 Model Makassar dan 44 orang (91.7\%) dari SMA Negeri 5 Makassar. Jumlah anggota Keluarga responden paling banyak memiliki 5-6 Orang sebanyak 20 orang (48.8\%) dari MAN 2 Model Makassar dan 21 orang (43.8\%) dari SMA Negeri 5 Makassar. Individu tumbuh dan berkembang dari sebuah keluarga. Selanjutnya masyarakat akan terbentuk dari komponen keluarga. Orang- 
orang yang termasuk dalam keluarga adalah ibu, bapak dan anak-anak. Bagi masyarakat menengah ke bawah, memiliki banyak jumlah anggota keluarga memiliki beban tersendiri dalam melanjutkan kehidupan sehari-hari. Dimana kondisi ekonomi yang sulit, orang tua cenderung lebih cepat menikahkan anak perempuannya karena paling tidak sedikit banyaknya mereka akan berkurang.

Pendidikan terakhir orang tua diperoleh bahwa sebagian besar responden memiliki pendidikan orang tua yang cukup tinggi dimana pendidikan terakhir ayah adalah strata 1 (S1) yaitu sebanyak 21 orang (51.2\%) dari MAN 2 Model Makassar dan 22 orang $(45.8 \%)$ dari SMA Negeri 5 Makassar sedangkan pendidikan ibu adalah strata 1 (S1) yaitu sebanyak 21 orang (51.2\%) dari MAN 2 Model Makassar dan 20 orang (41.7\%) dari SMA Negeri 5 Makassar. Kondisi diatas menunjukkan bahwa pendidikan memberikan dampak bagi pola pikir dan pandangan orang tua terhadap mendidik anaknya. Semakin tinggi pendidikan yang dimiliki orang tua maka semakin memperluas dan melengkapi pola berpikirnya dalam mendidik anaknya. Profesi pekerjaan orang tua diperoleh bahwa sebagian besar responden memiliki profesi pekerjaan ayah adalah pegawai negeri sebanyak 16 orang (33.3\%) dari SMA Negeri 5 Makassar dan pegawai swasta sebanyak 12 orang (29.3\%) dari MAN 2 Model Makassar sedangkan pekerjaan ibu adalah ibu rumah tangga (IRT) yaitu sebanyak 17 orang (41.5\%) dari MAN 2 Model Makassar dan 16 orang (33.3\%) dari SMA Negeri 5 Makassar. Kondisi diatas menunjukkan bahwa pekerjaan orang tua berkaitan dengan status ekonomi keluarga. Status ekonomi orang tua yang tinggi akan lebih sedikit menerima pernikahan di usia dini. Kemampuan orang tua untuk memiliki kendaraan kepada putra/putri sebagai alat transportasi ke sekolah sehari-hari menandakan pendapatan orang tua sudah memadai. Hal ini ditunjukkan sebagian besar menggunakan motor sebagai alat transportasi ke sekolah yaitu sebesar 22 orang $(53.7 \%)$ dari MAN 2 Model Makassar dan 28 orang (58.3\%) dari SMA Negeri 5 Makassar.

Selanjutnya, sebagian besar remaja tinggal bersama orang tuanya sebanyak 33 orang $(80.5 \%)$ dari MAN 2 Model Makassar dan 39 orang $(81.3 \%)$ dari SMA Negeri 5 Makassar.
Keluarga memberi pengaruh yang cukup besar bagi perkembangan remaja karena keluarga merupakan lingkungan sosial pertama yang meletakkan dasar-dasar kepribadian remaja. Kehadiran orang tua dalam kehidupan seorang anak di usia remaja sangat penting. Komunikasi yang disampaikan orang tua mengandung unsur kepatuhan yang berwenang yang dimiliki orang tua terhadap anak. Dalam kekuasaannya orang tua juga dapat meneguhkan aturan-aturan yang berlaku di keluarga.

\section{SUMBER INFORMASI PROGRAM PENDEWASAAN USIA PERKAWINAN}

Berdasarkan hasil penelitian diatas diperoleh bahwa responden sebagian besar mendapatkan informasi bersumber dari TV/Radio sebanyak 48 orang dimana 25 orang (61\%) dari MAN 2 Model Makassar dan 23 orang (47.9\%) dari SMA Negeri 5 Makassar.

\section{TINGKAT PEMAHAMAN REMAJA TERHADAP PROGRAM PENDEWASAAN USIA PERKAWINAN MELALUI FILM 'KEMBANG DESO' DI SMA NEGERI 5 MAKASSAR DAN MAN 2 MODEL MAKASSAR}

Dari tabel diatas diperoleh bahwa ratarata empiris untuk MAN 2 Model Makassar 45.41 dan SMA Negeri 5 Makassar 46.04.

Jika mengacu pada kriteria, maka hasil penelitian (tabel 2 diatas) menunjukkan bahwa tingkat pemahaman remaja di MAN 2 Model Makassar dan SMA Negeri 5 Makassar samasama pada kriteria sedang, dengan rincian, ada 24 responden $(58.5 \%)$ berasal dari SMA Negeri 5 Makassar dan 25 responden (52.1\%) berasal dari MAN 2 Model Makassar.

\section{SIKAP REMAJA TERHADAP PROGRAM PENDEWASAAN USIA PERKAWINAN MELALUI FILM 'KEMBANG DESO' DI SMA NEGERI 5 MAKASSAR DAN MAN 2 MODEL MAKASSAR}

Dari tabel 3 diatas diperoleh bahwa rata-rata empiris untuk MAN 2 Model Makassar 48.51 dan SMA Negeri 5 Makassar 51.15.

Jika mengacu pada kriteria, maka hasil penelitian (tabel 4 diatas) menunjukkan bahwa sikap remaja di MAN 2 Model Makassar pada kriteria netral sebanyak 22 Orang (53.7\%) dan 
SMA Negeri 5 Makassar pada kriteria setuju sebanyak 28 Orang (58.3\%).

\section{PERBEDAAN TINGKAT PEMAHAMAN DAN SIKAP REMAJA TERHADAP PROGRAM PENDEWASAAN USIA PERKAWINAN MELALUI FILM 'KEMBANG DESO' DI SMA NEGERI 5 MAKASSAR DAN MAN 2 MODEL MAKASSAR}

Hasil penelitian ini disimpulkan bahwa tidak ada perbedaan tingkat pemahaman remaja terhadap program Pendewasaan Usia Perkawinan melalui film 'Kembang Deso' di MAN 2

Model Makassar dan SMA Negeri 5 Makassar dimana nilai signifikan (2 tailed) diperoleh $\mathrm{T}_{\text {hitung }}(0.615)>\mathrm{T}_{\text {tabel }}(0.05)$ artinya Ho diterima. Namun, ada perbedaan sikap remaja terhadap program Pendewasaan Usia Perkawinan melalui film 'Kembang Deso' di MAN 2 Model Makassar dan SMA Negeri 5 Makassar dimana nilai signifikan (2 tailed) diperoleh $\mathrm{T}_{\text {hitung }}(0.011)>\mathrm{T}_{\text {tabel }}(0.05)$ artinya $\mathbf{H a}$ diterima.

\section{HUBUNGAN TINGKAT PEMAHAMAN DAN SIKAP REMAJA TERHADAP PROGRAM PENDEWASAAN USIA PERKAWINAN MELALUI FILM 'KEMBANG DESO'}

Dari data tabel 5 menunjukkan bahwa nilai signifikan $\mathrm{R}_{\text {hitung }}(0.843)>\mathrm{R}_{\text {tabel }}(0.05)$ maka diasumsikan bahwa Ho diterima artinya tidak ada hubungan tingkat pemahaman dengan sikap remaja terhadap program Pendewasaan Usia Perkawinan melalui film 'Kembang Deso'.

\section{PEMBAHASAN}

Dari hasil penelitian menunjukkan bahwa karakteristik responden pada kedua lokasi penelitian dapat digeneralisasikan adalah sama dimana golongan sosial responden cenderung sama, usia yang tergolong sama, sama-sama masih sekolah, ajaran agama Islam, sehingga cenderung memiliki pemahaman yang sama terhadap informasi yang disampaikan program Pendewasaan Usia Perkawinan melalui film 'Kembang Deso'. Responden pernah mengetahui program Pendewasaan Usia Perkawinan melalui iklan layanan masyarakat yang ditayangkan di televisi atau radio. Tingkat pemahaman remaja terhadap program pendewasaan Usia perkawinan melalui film di MAN 2 Model Makassar dan SMA Negeri 5 Makassar adalah sedang atau tahap pemahaman yang kedua, dimana tahap pemahaman penafsiran dimana responden mampu untuk mengenal dan memahami ide utama suatu komunikasi. Tidak ada perbedaan tingkat pemahaman remaja namun memiliki perbedaan sikap remaja terhadap program Pendewasaan Usia Perkawinan melalui film

'Kembang Deso' di SMA Negeri 5 Makasar dan MAN 2 Model Makasar. Sikap remaja terhadap program Pendewasaan Usia perkawinan melalui film 'Kembang Deso' di MAN 2 Model Makassar berada pada kriteria netral dan SMA Negeri 5 Makassar berada pada kriteria setuju. Sehingga pemahaman mereka tidak memiliki korelasi dengan sikap terhadap program PUP melalui film 'Kembang deso'. Menurut Gonzalez dalam Unde (2014), lebih lanjut menjelaskan bahwa ketiga jenis efek (kognitif, afektif dan konatif) ini berhubungan satu sama lain akan tetapi juga saling indenpenden, sehingga menimbulkan sesuatu pengaruh sekuen yang berbeda.

Dalam teori perbedaan individu mengungkapkan bahwa pesan-pesan media yang berisi stimulus menghasilkan respon yang berbeda-beda dari kalangan khalayak. Hal ini disebabkan oleh perbedaan-perbedaan atau karakteristik tiap-tiap individu, seperti usia, pekerjaan, agama dan sebagainya (Rakhmat, 2005). Hal ini disebabkan oleh faktor lingkungan sekolah merupakan lingkungan kedua remaja dalam bersosialisasi selain keluarga. Pada lingkungan ini memiliki banyak pengalaman yang membuat pembelajaran bagi remaja secara individu. Faktor lainnya, dimana remaja terjadi perubahan sosial. Ketika anak memasuki usia remaja dimana sangat membutuhkan kebebasan dan mereka mulai meninggalkan rumah, maka orang tua dapat melakukan penyesuaian terhadap keadaan tersebut. Dengan tinggal bersama orang tua maka komunikasi orang tua pada anak dapat dilakukan dalam bentuk kehadiran yang bukan saja secara fisik namun kebutuhan kognitif, afektif dan perilaku. Orang tua akan memiliki kesan yang lebih tinggi dibandingkan anggota keluarga lain seperti saudara kandung, saudara yang tinggal bersama atau kakek dan nenek (Singgih, 2004).

Menurut Baran (2011), mengungkapkan penonton televisi adalah orang yang berusia muda. Remaja dan orang dewasa bisa 
menghabiskan 8 jam sehari menonton televisi, pergi ke bioskop. Hal ini relevan dengan teori S-R (Stimulus-Respon) yang mengungkapkan bahwa media menyajikan stimuli perkasa yang secara seragam diperhatikan oleh massa (Cangara, 2014). Teori ini disebut juga teori jarum hypodermis dimana dianalogikan pesan komunikasi seperti menyebutkan obat yang disuntikkan dengan jarum ke bawah kulit pasien dengan reaksi obat yang menjalar cepat sehingga pasien tidak berdaya. Terkait dengan penelitian ini, film 'Kembang Deso' diibaratkan sebagai jarum suntik yang besar yang memiliki kapasitas sebagai perangsang (S) dan menghasilkan tanggapan (R) yang kuat pula.

Secara umum, responden SMA Negeri 5 Makassar dan MAN 2 Model Makassar diratakan paham akan pesan yang disampaikan film 'Kembang Deso', walaupun ada variasi tingkat pemahaman mereka. Efek ini berkaitan dengan pengetahuan responden memaknai film 'Kembang Deso' sesuai dengan apa yang diketahui, dipahami atau dipersepsi. Menurut Gonzalez dalam Unde (2014), efek media adalah konsekuensi dari apa yang meda massa perbuat baik sengaja maupun tidak sengaja. Disisi lain, 'kekuatan media' merujuk pada potensi umum dalam hal media memiliki efek terutama efek terencana. Pada penelitian ini yang dimaksud dengan efek kognitif adalah pemahaman mereka tentang program Pendewasaan Usia Perkawinan melalui film yang ditayangkan.

Seseorang mengerjakan sesuatu berdasarkan kepercayaan yang diperolehnya melalui pengetahuan yang ia pahami dan kemudian menjadi dasar opininya dan setelah itu akan membentuk attitude/sikap seseorang yang ditunjukkan dengan perilaku atau tindakan (Ruben,

2013). Hal ini relevan dengan McQuail (2011), yang menyatakan bahwa efek afektif berupa responden akan memberikan respon pada apa yang dirasakan, apakah mereka menyenangi atau membenci keadaan yang ditampilkan oleh film tersebut. Sikap menyenangi atau membenci lahir dari tinggirendahnya keterlibatan emosi, nilai dan motivasi intrinsik seseorang terhadap informasi atau pesan yang baru diterima atau didengarnya.

Adapun indikator yang menyebabkan perbedaan sikap tersebut adalah dampak yang akan terjadi bila menikah dini. Pada responden
MAN 2 Model Makassar cenderung tidak menyetujui bahwa dampak dari pernikahan dini adalah memiliki anak banyak, tidak dapat melanjutkan sekolah formal, terjadi perceraian dikemudian hari dan perekonomian akan morat-marit. Hal ini dimungkinkan karena paham-paham keagamaan yang sudah terbentuk dilingkungan sekolah dimana rejeki berasal dari Allah sehingga segala sesuatu yang terjadi dalam hidup sudah menjadi kehendakNya. Sebaliknya, pada responden SMA Negeri 5 Makassar cenderung menyetujui bahwa dampak dari pernikahan dini adalah memiliki anak banyak, tidak dapat melanjutkan sekolah formal, terjadi perceraian dikemudian hari dan perekonomian akan morat-marit.

\section{KESIMPULAN DAN SARAN}

Berdasarkan hasil penelitian, diperoleh kesimpulan berupa tidak ada perbedaan tingkat pemahaman remaja namun ada perbedaan sikap remaja terhadap program Pendewasaan Usia Perkawinan melalui film 'Kembang Deso' di SMA Negeri 5 Makassar dan MAN 2 Model Makassar. Indikator yang menyebabkan perbedaan sikap adalah dampak yang akan terjadi bila menikah dini. Kemudian, tidak ada hubungan yang signifikan antara tingkat pemahaman dengan sikap remaja terhadap program Pendewasaan Usia Perkawinan melalui film 'Kembang Deso'. Oleh karena itu, penulis merekomendasikan agar menggunakan film sebagai media sosialisasi yang lebih dekat dan mudah dipahami oleh kalangan remaja. Sedangkan untuk instansi terkait seperti BKKBN, Kementerian Komunikasi dan Informasi, Kementerian Pendidikan dan Kebudayaan diharapkan memberikan dukungan dalam pembuatan film yang bertemakan pendidikan pendewasaan usia perkawinan.

\section{UCAPAN TERIMA KASIH}

Penulis mengucapkan puji syukur dan terima kasih yang tak terhingga kepada Allah yang Baik dan Hebat, dosen pembimbing, dosen penguji, rekan kerja BKKBN Provinsi Sulawesi Selatan, orang tua, adik-adikku serta keluarga lainnya, sahabatku: Maria Yunita Sinaga, Socu Genk, temanteman pps komunikasi 2014, atas kerja sama dan dukungannya. Penulis merasa termotivasi menyusun dan menyelesaikan jurnal ini. Tanpa 
kalian, penulis bukan apa-apa. God Bless you all.

\section{DAFTAR PUSTAKA}

Arif W S. (2010). Perceraian Akibat Pernikahan Dini. Jogjakarta: UIN Sunan Kalijaga.

Baran S. (2011). Pengantar Komunikasi Massa: Literasi Media dan Budaya. Jakarta: Penerbit Salemba Humanika.

Cangara H. (2014). Pengantar Ilmu Komunikasi. Jakarta: PT. Rajagrafindo Persada.

Landung J. dkk. (2009) Studi Kasus Kebiasaan Pernikahan Usia Dini pada Masyarakat Kecamatan sanggalani Kabupaten Tana Toraja. Jurnal MKMI Vol.5 No/4, Hal. 89-94, Makassar.

Mc.Quail D. (2011). Teori Komunikasi Massa: Edisi 6 Buku 2. Jakarta: Penerbit Salemba Humanika.

Muchtar S. (2014) Pertumbuhan penduduk dan Kehidupan Sosial (online). Diakses pada tanggal

21 Januari 2016 pukul 19.20. available from : http://pastimenet.blogspot.co.id/2014/11/pertumbuh an-penduduk-dan-kehidupan.html

Rakhmat J. (2005) Psikologi Komunikasi. Bandung: PT. Remaja Rosdakarya.

Riduwan. (2008). Skala Pengukuran Variabel-Variabel Penelitian. Bandung: Penerbit Alfabeta Riswandi. (2009). Ilmu Komunikasi. Yogyakarta: Graha Ilmu.

Ruben D. dkk. (2013). Komunikasi dan Perilaku Manusia (Edisi 5). Jakarta: PT. Rajagrafindo Persada

Singgih D. dkk. (2004). Psikologi Perkembangan Anak dan Remaja. Jakarta: PT, BPK Gunung Mulia.
Unde A. (2014). Televisi dan Masyarakat Pluralistik. Jakarta: Penerbit Prenada 


\section{DAFTAR TABEL}

Tabel 1. Hasil SPSS Perhitungan Mean Empiris Tingkat Pemahaman Remaja (Sumber: Data Primer diolah 2016

\section{Group Statistics}

Asal Sekolah N Mean Std. Deviation Std. Error

Mean

\begin{tabular}{llcccc}
\hline Jumlah & $\begin{array}{l}\text { MAN 2 Model } \\
\text { Makassar }\end{array}$ & 41 & 45.41 & 5.983 & .934 \\
& $\begin{array}{l}\text { SMA Negeri 5 } \\
\text { Makassar }\end{array}$ & 48 & 46.04 & 5.705 & .824 \\
\hline
\end{tabular}

Tabel 2. Tingkat Pemahaman Remaja Terhadap Program Pendewasaan Usia Perkawinan Melalui film 'Kembang Deso' di SMA Negeri 5 Makassar dan MAN 2 Model Makassar (Sumber: Data Prime diolah 2016)

\begin{tabular}{|c|c|c|c|c|c|c|c|c|c|}
\hline \multirow[t]{3}{*}{ NO } & \multirow[t]{3}{*}{ ASAL SEKOLAH } & \multicolumn{6}{|c|}{ TINGKAT PEMAHAMAN REMAJA } & \multicolumn{2}{|c|}{ JUMLAH } \\
\hline & & \multicolumn{2}{|c|}{ RENDAH } & \multicolumn{2}{|c|}{ SEDANG } & \multicolumn{2}{|c|}{ Tinggi } & \multirow[b]{2}{*}{ Frek } & \multirow[b]{2}{*}{$\%$} \\
\hline & & Frek & $\%$ & Frek & $\%$ & Frek & $\%$ & & \\
\hline 1 & MAN 2 Model Makassar & 10 & 24.4 & 24 & 58.5 & 7 & 17.1 & 41 & 100 \\
\hline \multirow[t]{2}{*}{2} & SMA Negeri 5 Makassar & 12 & 25 & 25 & 52.1 & 11 & 22.9 & 48 & 100 \\
\hline & JUMLAH & 22 & 24.7 & 49 & 55.1 & 18 & 20.2 & 89 & 100 \\
\hline
\end{tabular}

Tabel 3. Hasil SPSS Perhitungan Mean Empiris Tingkat Sikap Remaja (Sumber: Data Prime diolah 2016)

1) Group Statistics

\begin{tabular}{|c|c|c|c|c|c|}
\hline & ASAL SEKOLAH RESPONDEN & $\mathrm{N}$ & Mean & Std. Deviation & $\begin{array}{l}\text { Std. Error } \\
\text { Mean }\end{array}$ \\
\hline \multirow[t]{2}{*}{ SIKAP REMAJA } & MAN 2 Model Makassar & 41 & 48.51 & 5.273 & .824 \\
\hline & SMA Negeri 5 Makassar & 48 & 51.15 & 4.248 & 613 \\
\hline
\end{tabular}

Tabel 4. Sikap Remaja Terhadap Program Pendewasaan Usia Perkawinan Melalui film 'Kembang Deso' di SMA Negeri 5 Makassar dan MAN 2 Model Makassar

\begin{tabular}{|c|c|c|c|c|c|c|c|c|c|}
\hline \multirow[t]{3}{*}{ No } & \multirow[t]{3}{*}{ Asal Sekolah } & \multicolumn{5}{|c|}{ Tingkat Sikap Remaja } & \multicolumn{3}{|c|}{ Jumlah } \\
\hline & & \multicolumn{2}{|c|}{ Tidak Setuju } & \multicolumn{2}{|c|}{ Netral } & \multirow{2}{*}{$\begin{array}{l}\text { Setuju } \\
\text { Frek }\end{array}$} & \multirow[b]{2}{*}{$\%$} & \multirow[b]{2}{*}{ Frek } & \multirow[b]{2}{*}{$\%$} \\
\hline & & Frek & $\%$ & Frek & $\%$ & & & & \\
\hline 1 & $\begin{array}{l}\text { MAN } 2 \text { Model } \\
\text { Makassar }\end{array}$ & 4 & 9.8 & 22 & 53.7 & 15 & 36.6 & 41 & 100 \\
\hline \multirow[t]{2}{*}{2} & $\begin{array}{l}\text { SMA Negeri } 5 \\
\text { Makassar }\end{array}$ & 0 & 0 & 20 & 41.7 & 28 & 58.3 & 48 & 100 \\
\hline & JUMLAH & 4 & 4.5 & 42 & 47.2 & 43 & 48.3 & 89 & 100 \\
\hline
\end{tabular}


Tabel 5. Hasil SPSS Uji Korelasi Tingkat Pemahaman dengan Sikap Remaja terhadap Program Pendewasaan Usia Perkawinan melalui film 'Kembang Deso' Correlations

\begin{tabular}{|c|c|c|c|}
\hline & & Tingkat & Sikap Remaja \\
\hline & & Pemahaman & \\
\hline & & Remaja & \\
\hline Tingkat Pemahaman Remaja & Pearson Correlation & 1 & .021 \\
\hline & Sig. (2-tailed) & & .843 \\
\hline & $\mathrm{N}$ & 89 & 89 \\
\hline Sikap Remaja & Pearson Correlation & .021 & 1 \\
\hline & Sig. (2-tailed) & .843 & \\
\hline & $\mathrm{N}$ & 89 & 89 \\
\hline
\end{tabular}

